Their surface was marked with ridses (6), and they had a central hollow divided by diaphragms."

I will examine these statements seriatim.

(I) The author appears to have been strangely ignorant of Sir William Dawson's magnificent discoveries of Calamites and other Carboniferous plants in the Devonian strata of North America, announced in his Report on the subject in $187 \mathrm{I}$.

(2) In 1874 I published in the Philosophical Transactions the detailed structure of extremely beautiful examples of Calamostachys Binneyana, and, since then, Prof. Weiss, of Berlin, has figured equally fine examples of Calamostachys Ludzigi. In the Philosophical Transactions for 188 I I further showed that this genus comprehended both homosporous and heterosporous forms. At the same time Calamostachys is not the fruit of Calamites.

(4) Both Sir William Dawson and Prof. Weiss have shown that the slender twigs of Calamites were abundantly supplied with verticils of linear leaves.

(5) This statement is true with an important limitation, which Dr. Goebel ignores; or, as a follower of M. Renault, he more probably rejects. Whilst the type of Calamitean organisation is unquestionably Equisetiform, their arborescent stems and branches contained an enormous xylem or woody cylinder, developed exogenously, which made them differ very widely from their degenerate living representatives.

(6) This is a repetition of the old fallacy, which regarded the vertical groovings of the surfaces of the inorganic casts of the fistular medullary cavity as belonging to the cortical surface. We have now numerous sections of the Calamitean cortex, no one of which exhibits the slightest trace of vertical flutings; they are all smooth.

On p. 281, speaking of heterosporous Lycopodiacea, the author accepts M. Renault's old conclusions that in Lepidodendron "there is no certain indication of secondary growth in thickness." "The connection of fossil stems capable of great increase in thickness, such as the Sigillarieæ and Calamodendron is at present questioned." These facts are no longer capable of being justly questioned. The structure of Lepidodendron Selaginoides alone suffices to settle the matter so far as that genus is concerned; to say nothing of the many other species that demonstrate the same fact. M. Grand'Eury himself, long one of the most influential questioners, has now recognised that the genus Arthropitus only represents the thick woody zone of a true Calamite. Prof. Stur, of Vienna, long ago demonstrated in an unanswerable manner the almost absolute identity of Calamites and Calamodendron ; and M..Renault himself, as I have already observed, has still more recently been compelled by the discovery of a Sigillarian fructification by M. Zeiller to alter his view respecting the Sigillariæ. He no longer insists that these cannot be Ciyptogams because their stems grow exogenously, but now hands over to his opponents, who have so long contended for the Lycopodiaceous affinities of this Sigillarian genus, all the vertically fluted examples of it.

Whilst deeming it desirable that his readers should be put in possession of the other side of the question to which he refers, it is only fair to Dr. Goebel to say he is himself aware that those questions are dealt with in a one-sided manner. In a footnote on p. 272 of the English translation the author says :- "The short description given in the text from Renault may serve at least to draw attention to these interesting types, in which there is much that is yet uncertain. We cannot enter here into disputed or doubtful points." At the same time it is to be lamented that the leading botanists of the world cannot give us palæontologists more of that valuable aid which their special studies would so well enable them to do. I do not yet despair of enlisting some of the Strasburgers, de Barys, Goebels, and Van Tieghems in this honourable service.

Owens College

\section{A Sparrow chasing Two Pigeons}

ON Sunday, I asked three men what they were observing, when they pointed out a sparrow chasing two pigeons.

The pigeons were evidently greatly alarmed at their pugnacious attendant, who took occasional pecks at them when flying underneath, and whenever possible. The sparrow lost ground when the others made their more rapid doubling, but soon came up with them again, and renewed its attack.

What was the original quarrel of course we do not know, but the persistency of the sparrow's attack greatly amused us.
Have any of your readers observed anything like this? or is there any record of the like?

Luton, Chatham, March I4

E. A. C.

\section{Top-shaped Hailstones}

I DREW attention to hailstones possessing the above form in Science Gossip of December 1884. These pellets, which fell in my garden at Polmont, Stirlingshire, on the morning of May 6, I884, were about one-fourth of an inch in length, and nearly three-sixteenths of an inch across. I did not see any horizontal stratification as observed by your correspondent Mr. Middlemiss, but found that each transverse section, when examined by a good lens, exhibited a fairly well-marked internal radiated fibrous structure, somewhat similar to that shown in sections of the mineral wavellite. Below are two (transverse

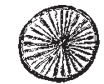

Frg. x.-Transverse section (near base of cone) $\times 2$.

and longitudinal) diagrammatic sections of the Polmont hailstones.

Since then, however, I have found top-shaped hailstones com-
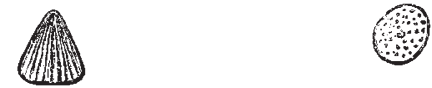

FIG. 3.-Longitudinal section. FIG. 4.-Transverse section of Fig. 3.

posed of fibres radiating from the summit of the pyramid as shown in Fig. 3.

Edinburgh University

\section{A Peculiar Radiation of Light}

AT $10.30 \mathrm{p} . \mathrm{m}$. this evening, my attention was called to a peculiar radiation of light in the eastern sky. The centre of radiation was due east, and the bars on the right-hand side were increased in brilliancy by light evidently arising from the moon, which was not visible, but concealed by cloud. The extent of these rays was from horizon to zenith; the rays being of unequal size, but of a pale gray colour, slightly iridescent.

The east wind was blowing smartly at the time, and I should like to be informed whether this strangely beautiful appearance in the sky was caused by the radiation of light from a rising moon on thin cloud;, or was it the effect of a strong current of wind from a given point?

By i p.m. the moonlight was full; the moon still to the right of the axis of the rays, and the rays nearly dispersed.

Falmouth, March 12

Robert D. Gibney

\section{THE CHEMICAL SOCIETY'S ANNIVERSARY $M E E T I N G$}

THE anniversary meeting of the Chemical Society was held on Wednesday, March 30 . We give some extracts from the address of the President, Dr. Hugo Müller, on the recent progress of chemical science :-

As we contemplate this ceaseless activity in chemical research now manifested all over the world, and which from year to year is continually on the increase, we are nevertheless bound to recognise the fact that vast as the work thus accumulated may appear, there remains still much to be accomplished. The more the field is worked the richer will be the harvest.

Overwhelmed by the quantity of material, especially in the direction of the production of new compounds, hasty critics were wont to denounce such work as superfluous, but it is now generally recognised that we must still continue with the patient and careful elaboration of the substructure of facts before we can with advantage proceed with the longed-for rearing of the edifice of a comprehensive scientific generalisation, that is to say, of ideal chemistry.

The infinite complexity which inquiry reveals in every 
direction bids us more than ever to be cautious in taking flight on the wings of speculation.

In the meantime we must content ourselves with the use of working hypotheses in the various fields of inquiry; these we develop and modify as we go on, or, it may be, discard in favour of others which for the time being seem more in accordance with the facts before us.

The triumphs of modern chemistry bear testimony that faulty and incomplete as our present theories undoubtedly are, our science is ever advancing.

It is now well understood that the most important data for the future extension of chemical theory will be derived from the interpretation of the results of investigations into the physical side of chemical phenomena.

The examination of the optical properties of chemical elements and compounds, the determination of thermochemical constants, and the verification of physical constants generally, are now pursued by a great number of investigators. Of late also the experimental inquiry into the connexion between electrical and chemical force is becoming a fruitful field of research; and we may hope that further determinations of the coefficients of conductivity of electrolytes will before long lead to a clearer perception of the intimate nature of chemical change.

To pass in review the chemical work published during the year, as some of my predecessors have done on similar occasions, has now become an impossible task, even supposing that the time at my disposal permitted me to do so. I am, however, tempted to refer briefly to a few results which strike me as particularly noteworthy.

The work accomplished in thermo-chemistry is, as I have already observed, very considerable, and thanks to the patient labour of many workers the results thus achieved are comprehensive enough to admit of a consideration of their general bearings. In this respect I wish to direct attention to the publication of Julius Thomsen's fourth and concluding volume of "Thermochemische Untersuchungen." This remarkable work is entitled to the highest appreciation of all who realise the manifold difficulties which beset the execution of thermochemical investigation. But while referring to the many highly important and remarkable deductions which the author draws from his experiments, we cannot at the same time help being struck by the many anomalous results and startling conclusions which he arrives at. It would seem that further determinations of the fundamental values, if possible by different and varied experimental methods, must be obtained before the full importance of this work can be entirely realised.

An important addition to our still very limited knowledge of the density of metallic elements in the gaseous state has been made by V. Meyer and Mensching, who have now succeeded in overcoming the great experimental difficulties formerly encountered in the determination of the vapour-density of zinc. The molecule of zinc has been found to be monatomic, like that of cadmium and of mercury, the only two other metals the vapour-densities of which are thus far known.

The remarkable results recently published by Crookes in his papers on the spectra of the so-called rare earths are still fresh in our memory, and the ingenious application he has made of the doctrine of evolution in this speculation on the genesis of the elements has not failed to attract the attention it deserves.

The further investigations of the chemical and physical properties of the new element germanium by Winkler, Nilson, and Petterson have established its chemical position, and the supposition that its proper place in the periodic system is that of ekasilicon has been confirmed.

Ladenburg's long-continued researches on conine have been crowned by success. He has effected its synthesis and has shown that it is identical with $a$-propylpiperidine. This must indeed be considered one of the most noteworthy achievements in organic chemistry of the past year, inas- much as it is the first instance of the artificial formation of an optically active natural alkaloid.

Wallach found that the diazo-amido-compounds formed from diazo-salts and piperidine are for the most part wellcharacterised substances, and that when heated with concentrated hydrofluoric acid they yield the fluor-derivative in almost theoretical proportions. He has prepared in this way fluorbenzene, parafluortoluene, parafluornitrobenzene, parafluoraniline, and fluorphenyl, \&c.

Studying the action of sodium on mixtures of ethers such as oxalic and acetic ethers, W. Wislicenus has discovered a new and ready method of effecting the synthesis of compound acids, and this reaction cannot fail to become of great value.

Brieger has succeeded in isolating a well-characterised alkaloid from the liquid used for cultivating a certain Bacillus which causes tetanus traumaticus in animals. This substance, which the author calls tetanine, seems to be the immediate cause of the toxic action of this Bacillus, and thus for the first time a specific pathological effect of a microbe has been traced to a well-defined chemical compound produced or secreted in its life-process.

Finally, I must also allude to the very remarkable observation recently published by Liebreich which demonstrates the fact that under certain conditions chemical reaction is retarded, and even altogether suspended. $\mathrm{He}$ noticed that in a mixture of aqueous solutions of chloral hydrate and sodium carbonate the formation of chloroform does not take place uniformly throughout the liquid. For instance, on performing the experiment in a test-tube there appears immediately below the meniscus a sharply defined space of $\mathrm{I}-3 \mathrm{~mm}$. thickness in which no reaction takes place. Similar results were obtained when an aqucous solution of iodic acid was mixed with sulphurous acid and soluble starch. The inert space manifests itself on the surface of the liquid which is in contact with the air or separated from it by a thin membrane: In narrow tubes the reaction is much more retarded, and it is altogether suspended in capillary tubes.

In my opinion this preliminary communication contains the germs of a discovery in a new direction, and the further study of the nature of these subtle influences which bring about the phenomenon in question must lead to important results.

In bringing this report to a conclusion I must briefly allude to a subject only indirectly connected with our Society, viz. the progress made in the organisation of technical education in this country, which, more particularly under the guidance and fostering care of the City and Guilds of London Institute, is gradually making its way.

Most of you are aware that the President of this Society is one of the ex officio members of the governing and organising body of this Institute, and it may be mentioned in passing that the regular attendance at the frequent meetings of the various Committees and SubCommittees involves the necessity of devoting a by no means inconsiderable amount of time to this honorary office.

The chief event to be recorded in this connexion is the inauguration of the Central Institution which is to fulfil the function of a Technical University or Polytechnicum, and to afford higher scientific education to the future owners, directors, managers, engineers of manufacturing works, and the teachers in the various branches of technology. This magnificent Institution has now started on its career, and we have every reason to think that before long its value will be fully recog. nised by those who ought to take advantage of its existence. It is, however, unfortunate that the organisation of this Institution has stopped short of the plans originally laid down, and has been not at once carried to completion. Strange as it may appear, this is due to the want of funds. The City and Guilds, in taking so pro- 
minently charge of the initiation and diffusion of technical education in this country, have thus far most liberally furnished the means required, and have thus earned the gratitude of the country ; but as the development of the scheme progresses an even and commensurate flow of further contributions is required, which, being voted in many cases but annually, at once demonstrates the somewhat precarious conditions on which this important enterprise is dependent.

It is to be hoped that a more general recognition of the absolute need of an education of a higher scientific character both for masters and men will before long have its proper effe:t; and that the ways and means will be forthcoming to carry out a work which promises so well, and that the Central Institution may then stand a fair comparison with numerous institutions of a similar kind in other countries which have already helped in so marked a degree to advance the industries of those countries.

The mistaken notion is still too prevalent that technical education has to confine itself to the theoretical considerations of known technical processes, and that a more extended acquisition of scientific knowledge is not required. It is obvious that a pupil educated on these lines may find by the time he is able to enter on his practical career that the processes with which he has been made acquainted have in the meanwhile become obsolete, and unless his education has been sufficiently comprehensive to enable him to strike out new lines for himself he will be ill fitted to compete with those who have been educated on a wider basis.

Essential as it is to impart to the future manager scientific knowledge, it is: above all necessary to train him by practical work and research in the laboratory how to investigate a subject which may present itself in his daily occupation, whether it be some unexpected development in a new direction, or whether it be some new difficulty which confronts him in carrying out the processes under his direction.

It is self-evident that such knowledge and such practical experience in carrying out investigations is not to be attained by merely attending one or two courses in the lecture-room or in the laboratory. Those who mean to effectually qualify themselves for such functions can only accomplish this object by devoting years of patient and intelligent work under the guidance of the professor in properly appointed laboratories.

\section{THE INSTITUTION OF NAVAL ARCHITECTS}

THE spring meetings of the Institution of Naval Architects this year were, to a considerable extent, Denny, of Dumbarton, the eminent shipbuilder, who was for many years one of the most active members of the Council, and who was foremost amongst the mercantile shipbuilders of this country in the application of scientific methods to naval architecture. Mr. Denny, as is well known, set up at Dumbarton a large experimental tank similar to that contrived by the Admiralty at Torquay for the late Mr. W. Froude, F.R.S., and in which most of his famous experiments on the resistances of the hulls of ships were carried out. It is not often that manufacturers can be induced to spare time and money for the purposes of scientific investigation, even when such investigation is directly conducive to the success of their business. But Mr. Denny was an exceptional man. He firmly believed in the mercantile value of exact scientific knowledge, and he possessed the courage and the ability to act up to his beliefs. It is satisfactory to know that he considered himself fully repaid for the risks he ran, in the results which he attained.

The opening address of the President dealt, as might have been expected in this Jubilee year, with the remark- able progress in steam navigation achieved during the fifty years of Her Majesty's reign; a progress which must certainly be acknowledged to be extraordinary when we remember that, at the commencement of the reign, the late Dr. Lardner publicly offered to eat the first steamship which should cross the Atlantic, whereas nowadays we have vessels which make the passage in a few hours over six days, and a fuel consumption at sea of $1 \frac{1}{4}$ pounds of coal per indicated horse-power per hour is not uncommon. The speaker alluded to the various improvements, such as the use of steel in the construction of both hulls, engines, and boilers, the adoption of highpressure steam and triple compounding, \&c., which have principally contributed to the remarkable results attained.

The first paper read was by the late Director of Naval Construction at the Admiralty, Sir Nathaniel Barnaby, and dealt with the important subject of the connexion between the Royal Navy and the merchant service. This paper was rather political than technical in its character. The author's main object was to support the Admiralty in their recently announced policy of so organising the mercantile marine as to increase the power of national defence. He pointed out that a fast and properly constructed mail steamer may be as efficient a factor in naval war as an ordinary cruiser costing a quarter of a million sterling; and that there are even certain services which the mail-steamer, by reason of her greater size and travelling power, can perform better than the cruiser. On the other hand, the great mass of our mercantile marine is now relatively weaker than it has ever been before against the attacks of an enemy ; for in the wars of the last century such ships as the armed East Indiamen possessed a well-recognised fighting value, but nowadays warships are so specialised that the majority of merchant vessels possess no powers of resistance whatever. Sir Nathaniel Barnaby also called attention to the fact that the State makes provision annually for a reserve of seamen, who are drilled periodically and paid by it, and who are liable to be called out to serve in case of war; and he then proceeded to show how, by good organisation, the superior merchant-ships, if manned mainly by naval reserve men, could in case of war be immediately available for service in whatever part of the world they might chance to find themselves. At the present moment the Royal and mercantile navies are under the control of two different Departments of State, and by some strange perversity the First Lord of the Admiralty is almost the only great political officer of State whose name is not to be found on the long list of members of the Board of Trade. As a natural consequence there is no community of action between the two Departments, and no organisation at present exists by which the services of the better class of fast merchant steamers could be rendered instantly available in case of war. The author's cure for this condition of affairs is the creation of a Secretaryship of State for the Navy, so that the interests of the merchant shipping and the Royal Navy might be united, and a truly national marine formed. There is no doubt but that Sir Nathaniel Barnaby in reading this paper has called attention to a very serious set of evils, which may all be remedied by a little organisation and by co-operation between two of the Departments of State. Even if the Board of Trade did not see its way to help in the work, what is to prevent the Post Office authorities from backing up the Admiralty by declaring that they would in future give the preference for mail-carrying purposes to steamers which fulfilled the Admiralty requirements of speed, subdivision, and structural strength, and what is to prevent the Admiralty from assisting the Post Office to obtain a cheap and efficient mail service by granting moderate retaining fees or subsidies to such steamers, provided they were always manned with a due proportion of naval reserve 